\title{
Incidence and Direct Medical Cost of Adjustment Disorder and in Korea Using National Health Insurance Service Claims Data From 2011 to 2017
}

\author{
Kyo-Jin Yang ${ }^{1}$, Seung-Mi Choi ${ }^{2}$, Si-Young Kim ${ }^{1}$, In-Hwan $\mathrm{Oh}^{3}$, \\ Saengryeol Park ${ }^{4}$, Hyeon-Kyoung Cheong ${ }^{3}$, and Jun-Won Hwang ${ }^{1} \bowtie$ \\ ${ }^{1}$ Department of Psychiatry, Kangwon National University Hospital, Kangwon University School of Medicine, Chuncheon, Republic of Korea \\ ${ }^{2}$ Kwangwoon University Graduate School of Education, Seoul, Republic of Korea \\ ${ }^{3}$ Department of Preventive Medicine, School of Medicine, Kyung Hee University, Seoul, Republic of Korea \\ ${ }^{4}$ Department of Physical Education, School of Education, Chonnam National University, Gwangju, Republic of Korea
}

\begin{abstract}
Objective We aimed to investigate the annual incidence and direct medical cost of adjustment disorder in general population using the National Health Insurance Service Database (NHID) in Korea.

Methods To examine the incidence, we selected patients who had at least one medical claim for adjustment disorder and had not been diagnosed in the previous 365 days, from 2010 to 2017.

Results The number of newly diagnosed cases of adjustment disorder from 2011 to 2017 were total 101,922. Annual incidence of adjustment disorder was ranged from 22.0 to 36.8 per 100,000 persons. The incidence of adjustment disorder was found more in female and highest among 70-79 years of age group and medical aid beneficiaries group. Annual prevalence of adjustment disorder was in the range from 95.4 to 116.4 per 100,000 persons. Estimated annual medical cost per person of adjustment disorder was ranged from 162 to 231.4 US dollars.

Conclusion From 2011 to 2017, the annual incidence and direct medical cost of adjustment disorder in Korea were increased. Proper information on adjustment disorder will not only allows us to accumulate more knowledge but also lead to more appropriate therapeutic interventions.

Psychiatry Investig 2021;18(8):789-794
\end{abstract}

Key Words Adjustment disorder; Incidence; Prevalence; Direct medical cost.

\section{INTRODUCTION}

In the Diagnostic and Statistical Manual, 5th edition (DSM-5), adjustment disorder is defined by the development of emotional or behavioral symptoms in response to an identifiable stressor occurring within 3 months of the onset. ${ }^{1}$ These symptoms or behaviors are clinically significant with marked distress that is out of proportion to the severity or the intensity of stressor and with significant impairment in social, occupation-

Received: December 22, 2020 Revised: June 5, 2021

Accepted: June 9, 2021

$\triangle$ Correspondence: Jun-Won Hwang, MD, PhD

Department of Psychiatry, Kangwon National University Hospital, Kangwon University School of Medicine, 156 Baengnyeong-ro, Chuncheon 24289, Republic of Korea

Tel: +82-33-258-2201, Fax: +82-33-258-2348, E-mail: huangjw@hanmail.net

(c) This is an Open Access article distributed under the terms of the Creative Commons Attribution Non-Commercial License (https://creativecommons.org/licenses/by$\mathrm{nc} / 4.0$ ) which permits unrestricted non-commercial use, distribution, and reproduction in any medium, provided the original work is properly cited. al, or other important areas of functioning. Subtypes of adjustment disorder may include depressed mood, anxiety, disturbance of conduct, and any combinations of such symptoms. Since adjustment disorder was included in the Diagnostic and Statistical Manual, 3rd edition (DSM-III) in 1980 and International Classification of Disease, 10th edition (ICD-10) in 1993, 2,3 it has been regarded as one of the most frequently diagnosed mental disorders in clinical practice. ${ }^{4}$ However, it has not received enough academic attention, which would cause the exact nature of adjustment disorder to be remained unknown. In addition, it has been known that adjustment was often unrecognized. ${ }^{5}$

In general, adjustment disorder seemed to be very prevalent in primary care settings where the long-term impact of illness and related psychosocial problems were common. In a population-based study in old age groups, a point prevalence of adjustment disorder was $2.3 \%{ }^{6}$ In a recent study which was 
performed to develop a diagnostic instrument for adjustment disorder in 323 individuals claiming disability benefit after 2 years of sickness absence due to any medical conditions, the prevalence of adjustment disorder was $7.4 \%{ }^{7}$ In addition, a point prevalence of adjustment disorder was found in 15.4\% of patients in palliative care settings and in $19.4 \%$ of patients in hemato-oncological care settings, respectively. ${ }^{8}$ However, none of previous major epidemiological studies including the Epidemiologic Catchment Area (ECA) study, the National Comorbidity Survey, and the Household Survey have included adjustment disorders, ${ }^{9-11}$ although it was already suggested that adjustment disorders are common in general population since formal criteria of adjustment disorder were established. ${ }^{2,3}$

Thus, there were only a few studies regarding the prevalence of adjustment disorder in general population. Using the Schedule for Clinical Assessment in Neuropsychiatry (SCAN), Casey et al. ${ }^{12}$ estimated the prevalence of adjustment disorder was $0.3 \%$. Using a questionnaire including a life events checklist and self-rating items regarding symptoms of adjustment disorder and symptom duration, Maercker et al. ${ }^{13}$ reported that the prevalence of adjustment disorder ranged from $0.9 \%$ to $1.4 \%$ according to clinical impairment. To our best of knowledge, there have been no studies regarding the annual incidence and direct medical costs of adjustment disorder in general population. As adjustment disorder is common diagnosis in a primary care setting and can be best treated by members of multidisciplinary team in psychiatric clinic with appropriate skills, ${ }^{14}$ there would be a need for comprehensive information regarding adjustment disorder across primary care settings.

The National Health Insurance Database (NHID) which is a public database operated by the Korean National Health Insurance Service (NHIS) was founded in 2012 and have contained almost all medical claims data in Korea. ${ }^{15}$ NHID have provided information on not only health care utilization but also health screening, socio-demographics, dates of death, and Korean Standard Classification of Diseases (KCD) diagnostic codes, which has been based on ICD-10. ${ }^{3}$ Given the scarcity of previous reports regarding the incidence, the prevalence, and the economic burden of adjustment disorder, NHID would be an important resource for examining the epidemiology of adjustment disorder. The current study was performed in order to ascertain the number of people who were newly diagnosed with adjustment disorder annually from 2011 to 2017, and to estimate direct medical cost in people with adjustment disorder.

\section{METHODS}

\section{Data sources}

Data from NHIS were used for this study. ${ }^{15}$ NHIS is the sin- gle insurer in South Korea, operated by the South Korean government. We used the database of NHIS where the database is structured with health service utilization, regular health checkup, economic status based on national health insurance premium, age, and etc. In NHID, there could be 10 diagnosis that consisted of 1 main diagnosis and 9 sub-diagnosis, which were made by clinicians according to the diagnosis criteria in the ICD-10. In addition, the database further provides insurance types, consisted of insured employees, self-employed individuals, medical aid beneficiaries). For detailed analyses, socio-economic status of self-employed individuals and insured employees were categorized by 5 groups (e.g., very low, low, middle, high, and very high as income level) according to the quintiles of their income. In case of missing cases in gender and age, we excluded them from analysis. All costs were presented in US dollar (USD) using the exchange rates in 2017 from Statistics Korea. ${ }^{16}$

\section{Case definition}

Adjustment disorders were defined using the ICD-10 in which it is coded as F43.2. ${ }^{3}$ We chose patients with the code of F43.2 as their main diagnosis in the NHID from 2011 to 2017.

\section{Incidence rates of adjustment disorder}

From 2011 to 2017, annual incidence of adjustment disorder per 100,000 persons was estimated by dividing the number of patients with adjustment disorder by the number of total population in South Korea. Patients were defined as valid when they had track records of visiting or inpatient admissions with adjustment disorder. Those who had any records of adjustment disorder within a year were excluded.

\section{Prevalence rates of adjustment disorder}

Annual prevalence of adjustment disorder was calculated from 2011 to 2017. To estimate the prevalence per 100,000 persons, the number of patients with adjustment disorder was also divided by the number of total population of South Korea according to records of visiting outpatient clinics or inpatient admissions.

\section{Estimation of direct medical costs of adjusment disorder}

The direct medical costs of adjustment disorder were estimated by summing both costs of outpatient visits and inpatient admissions. The total medical costs were divided by the number of population of South Korea to estimate the total medical costs per a person. The direct medical costs were calculated on the basis of a prevalence-based approach and converted to USD (exchange rate 1,071 Korean Won=1 USD in 2017). Statistical analysis (SAS ver. 9.2; SAS institute Inc., Cary, NC, 
USA) was employed for all statistical analyses.

\section{Ethics statement}

A research ethics was award by the Institutional Review Board of Kangwon University Hospital (IRB No. 2018-09-008003). An informed consent from patients was not required due to the nature of public data from NHIS.

\section{RESULTS}

From 2011 to 2017, total number of patients with adjustment disorder and the incidence of adjustment disorder were increased consistently. The number of newly diagnosed patients were 11,029 in 2011 and reached to 18,850 in 2017. In addition, the annual incidence of adjustment disorder was 22.0 per 100,000 persons in 2011 and 36.8 per 100,000 persons in 2017. During this period, the number of patients and the annual incidence in female were higher than those in male (Table 1).

The incidence of adjustment disorder according to age groups was presented in Table 2 . The highest number of newly diagnosed patients were found in 50-59 years of age group. However, considering cumulative number of population from 2011 to 2017 in each age group, the incidence was highest in 70-79 years of age group.

The incidence of adjustment disorder according to insurance types was presented in Table 3. The highest number of newly diagnosed patients were found in self-employed individuals group. However, the incidence of adjustment disorder was highest in medical aid beneficiaries group, as the number of patients was divided by cumulative number of population from 2011 to 2017 in each group.

When we divided patients with adjustment disorder into 6 groups by income (i.e., very high, high, middle, low, very low, and medical aid beneficiaries group), the number of patients was highest in very high income group and lowest in medical aid beneficiaries group (Figure 1). Although the order of the number of patients by year seemed to be mixed in part, high number of patients was found in order of very high income group, high income group, middle income group, very low income group, low income group, and medical aid beneficiaries group in 2017 (Figure 1). As the exact number of population in any groups by years was not available, the changes in the incidence of adjustment disorder in each 6 group could not be calculated.

We also estimated prevalence and direct medical cost of patients with adjustment disorder from 2011 to 2017. The number of all patients with adjustment disorder and the prevalence of adjustment disorder in 2017 were higher than those in 2011. In addition, annual prevalence of adjustment disorder was in the range from 95.4 to 116.4 per 100,000 persons. Higher number of all patients and higher prevalence were found in order of $2017,2016,2012,2011,2015,2013$, and 2014, respectively.

Table 2. Number of patients and incidence of adjustment disorders in South Korea from 2011 to 2017 by age groups

\begin{tabular}{lccc}
\hline Age & $\begin{array}{c}\text { Number } \\
\text { of newly } \\
\text { diagnosed } \\
\text { patients }\end{array}$ & $\begin{array}{c}\text { Incidence } \\
\text { (per 100,000 } \\
\text { persons) }\end{array}$ & $\begin{array}{c}\text { Cumulative } \\
\text { number } \\
\text { of population } \\
\text { from 2011 to 2017 }\end{array}$ \\
\hline $0-9$ & 1,095 & 3.4 & $32,306,397$ \\
$10-19$ & 10,248 & 24.1 & $42,511,005$ \\
$20-29$ & 12,680 & 27.2 & $46,650,614$ \\
$30-39$ & 12,554 & 22.9 & $54,830,517$ \\
$40-49$ & 17,701 & 29.0 & $61,129,933$ \\
$50-59$ & 19,921 & 36.1 & $55,226,437$ \\
$60-69$ & 14,435 & 44.2 & $32,655,585$ \\
$70-79$ & 10,058 & 47.5 & $21,169,723$ \\
$\geq 80$ & 3,230 & 37.6 & $8,594,095$ \\
\hline
\end{tabular}

Table 1. Number of patients and incidence of adjustment disorders in South Korea from 2011 to 2017 (per 100,000 persons)

\begin{tabular}{cccccccccc}
\hline Year & $\begin{array}{c}\text { Number } \\
\text { of newly } \\
\text { diagnosed } \\
\text { male } \\
\text { patients }\end{array}$ & $\begin{array}{c}\text { Incidence } \\
\text { in male } \\
\text { (per 100,000 } \\
\text { persons) }\end{array}$ & $\begin{array}{c}\text { Number } \\
\text { of newly } \\
\text { diagnosed } \\
\text { female } \\
\text { patients }\end{array}$ & $\begin{array}{c}\text { Incidence } \\
\text { in female } \\
\text { (per 100,000 } \\
\text { persons) }\end{array}$ & $\begin{array}{c}\text { Total } \\
\text { number } \\
\text { of newly } \\
\text { diagnosed } \\
\text { patients }\end{array}$ & $\begin{array}{c}\text { Incidence } \\
\text { in general } \\
\text { population } \\
\text { (per 100,000 } \\
\text { persons) }\end{array}$ & $\begin{array}{c}\text { Number } \\
\text { of total } \\
\text { male } \\
\text { population }\end{array}$ & $\begin{array}{c}\text { Number } \\
\text { of total } \\
\text { female } \\
\text { population }\end{array}$ & $\begin{array}{c}\text { Number } \\
\text { of total } \\
\text { population }\end{array}$ \\
\hline 2011 & 4,569 & 18.2 & 6,460 & 25.8 & 11,029 & 22.0 & $25,081,788$ & $25,029,688$ & $50,111,476$ \\
2012 & 5,400 & 21.4 & 7,544 & 30.0 & 12,944 & 25.7 & $25,187,494$ & $25,157,831$ & $50,345,325$ \\
2013 & 5,570 & 22.0 & 7,759 & 30.7 & 13,329 & 26.4 & $25,282,928$ & $25,276,024$ & $50,558,952$ \\
2014 & 5,914 & 23.3 & 8,129 & 32.0 & 14,043 & 27.7 & $25,374,486$ & $25,388,672$ & $50,763,158$ \\
2015 & 6,697 & 26.3 & 8,681 & 34.1 & 15,378 & 30.2 & $25,458,058$ & $25,493,662$ & $50,951,720$ \\
2016 & 7,235 & 28.3 & 9,114 & 35.6 & 16,349 & 32.0 & $25,527,815$ & $25,585,157$ & $51,112,972$ \\
2017 & 8,464 & 33.1 & 10,386 & 40.5 & 18,850 & 36.8 & $25,576,752$ & $25,653,952$ & $51,230,704$ \\
\hline
\end{tabular}


Incidence and Medical Cost of Adjustment Disorder

Table 3. Number of patients and incidence of adjustment disorders in South Korea from 2011 to 2017 by insurance type (per 100,000 persons)

\begin{tabular}{lccc}
\hline \multicolumn{1}{c}{ Insurance types } & $\begin{array}{c}\text { Number of newly } \\
\text { diagnosed patients }\end{array}$ & $\begin{array}{c}\text { Incidence } \\
\text { (per 100,000 persons) }\end{array}$ & $\begin{array}{c}\text { Cumulative number of population } \\
\text { from 2011 to 2017 }\end{array}$ \\
\hline Medical aid beneficiaries & 8,162 & 77.3 & $10,555,637$ \\
Self-employed individuals & 63,893 & 61.6 & $103,693,069$ \\
Insured employees & 29,867 & 12.1 & $247,768,522$ \\
\hline
\end{tabular}

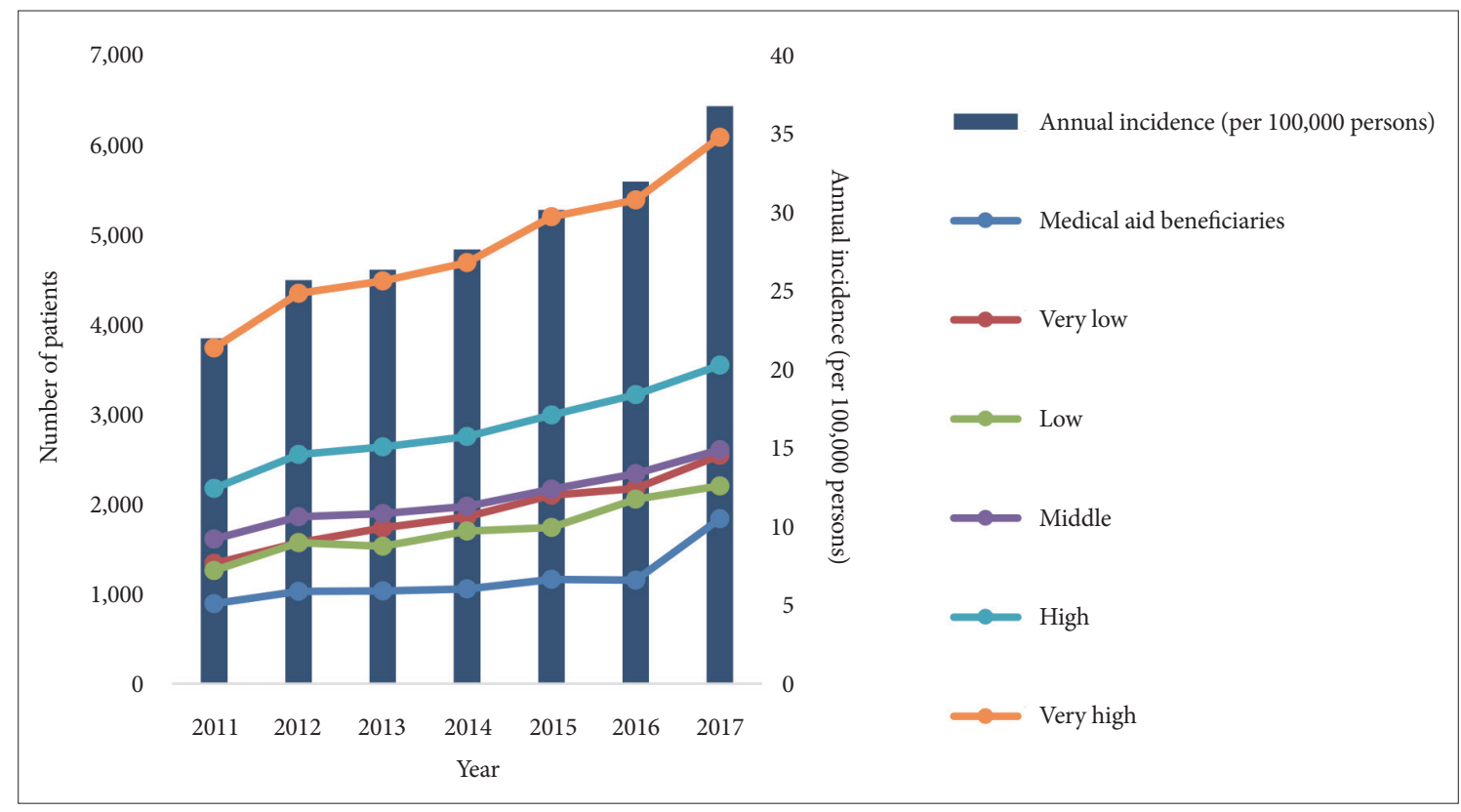

Figure 1. Incidence of adjustment disorders in South Korea from 2011 to 2017 by economic status (per 100,000 persons).

Table 4. Medical costs and prevalence of adjustment disorders in South Korea from 2011 to 2017

\begin{tabular}{lrrrrrrr}
\hline \multicolumn{1}{c}{ Year } & \multicolumn{1}{c}{2011} & \multicolumn{1}{c}{2012} & \multicolumn{1}{c}{2013} & \multicolumn{1}{c}{2014} & \multicolumn{1}{c}{2015} & 2016 & 2017 \\
\hline Number of all patients & 53,312 & 54,197 & 48,438 & 48,406 & 49,982 & 55,391 & 59,607 \\
Prevalence (per 100,000 persons) & 106.4 & 107.7 & 95.8 & 95.4 & 98.1 & 108.4 & 116.4 \\
Total cost & $8,645,443$ & $9,271,468$ & $9,337,028$ & $9,737,713$ & $9,607,181$ & $10,709,996$ & $13,792,781$ \\
$\quad$ Outpatient (psychiatry) & $6,225,166$ & $6,738,505$ & $6,656,555$ & $6,995,091$ & $7,099,200$ & $8,028,755$ & $11,062,588$ \\
Outpatient (non-psychiatry) & 502,400 & 532,870 & 556,762 & 598,096 & 562,140 & 585,997 & 138,262 \\
Inpatient (psychiatry) & $1,678,388$ & $1,649,473$ & $1,751,833$ & $1,798,931$ & $1,683,796$ & $1,830,196$ & $2,294,695$ \\
$\quad$ Inpatient (non-psychiatry) & 239,488 & 350,618 & 371,877 & 345,596 & 262,046 & 265,048 & 297,236 \\
Total cost (per person) & 162 & 171 & 193 & 201 & 192 & 193 & 231.4 \\
\hline
\end{tabular}

1 US dollar=1,152 Korean won (mean exchange rate in 2011); 1,071 (2012); 1,055 (2013); 1,099 (2014); 1,173 (2015); 1,208 (2016); 1,071 $(2017)^{16}$

Total direct medical cost of adjustment disorder was continuously increased except 2015 and the total direct medical cost per person was 231.4 USD in 2017. Most direct medical cost was claimed by outpatient clinics and inpatient unit from psychiatric department (Table 4).

\section{DISCUSSION}

To our best of knowledge, the current study is the first one reporting the annual incidence of adjustment disorder in general population. From 2011 to 2017, the annual incidence of adjustment disorder in Korea was in the range from 22.0 to 36.8 per 100,000 persons and increased continuously. During the same period, the annual prevalence rate of adjustment disorder was 106.4 per persons in 2011 and reached to 116.4 per 100,000 persons. These increases may be partly explained by increased perception of stress as common one that should be managed properly in Korea, ${ }^{17}$ although social stigma to- 
wards mental illness has been still present. ${ }^{18}$ The annual prevalence of adjustment disorder in general population in the current study is lower than expected from the results of previous study in general population. ${ }^{12,13}$ This difference might be caused by study methods and biased sample. Because the results in the current study was derived from claims data, only those who intended to be diagnosed and treated would be included as patients in NHID. Considering remained social stigma towards mental illness, ${ }^{18}$ it seemed that most patients those experience significant stress should tolerate and would remain untreated. In addition, some patients would be treated by psychosocial treatment outside medical settings (e.g., workrelated counselling centers in their workplaces, private counselling centers, public counselling centers, etc.).

There has been no previous studies regarding annual incidence of adjustment disorder, although the prevalence of adjustment disorder in general population has been estimated in a few studies. In Casey et al.s study, ${ }^{12} 14,387$ adults aged between 18 and 64 from 5 countries including Ireland, Britain, Norway, Finland, Spain were screened by Beck Depression Inventory (BDI) with the cut-off score of 13. Those scoring 13 and more in BDI were interviewed using the Schedule for Clinical Assessment in Neuropsychiatry (SCAN) in which ICD-10 diagnosis of adjustment disorder could be made. After these 2 stage screening method was administered, in approximately 6,800 individuals, the overall weighted prevalence of adjustment disorder was $0.3 \%$. In this study, it seemed that adjustment disorder was found more in rural area, female, not single, and aged 30 and more groups, respectively. In Maercker et al. s $^{13}$ study, 2,511 participants aged between 14 and 93 in Germany were evaluated using questionnaires including life-events checklist in which 7 types of acute stressful events (e.g., divorce, moving, etc.) and 10 types of chronic stressors (e.g., conflict with neighbors, serious illness, etc.) could be assessed and self-rating items regarding symptoms of adjustment disorder and symptom duration, and impairment. They reported that $0.9 \%$ of the sample could be diagnosed with adjustment disorder with the impairment criteria and that $1.4 \%$ was diagnosed with adjustment disorder unfulfilling the impairment criteria. In this study, adjustment disorder was found more in female. In addition, higher prevalence rates were found in order of middle-aged adults, older adults, and young adults, respectively.

In partial accordance with these results, ${ }^{12,13}$ the number of patients and the incidence rate in female was higher than those in male in the current study. While the number of newly diagnosed was highest in 50-59 years of age group, actual incidence rate was highest in 70-79 years of age group in the current study when we took into account the cumulative number of population in each group. As the number of elderly popu- lation has been increased rapidly in last decades in Korea, it was expected that it would take 18 years to be changed from an aging society to an aged society from 2000 to $2018 .{ }^{19,20} \mathrm{In}$ addition, the economic poverty despite of increase in economic activity participation and separation from original family members in elderly population has been increased recently. ${ }^{21}$ All these change seemed to be significant stressors which were related to the increase in the annual incidence of adjustment disorder in elderly population.

Similarly, although the highest number of newly diagnosed patients with adjustment disorder were also found in self-employed individuals, highest incidence rate was also found in medical beneficiaries group, taking into account the cumulative number of population. When we divided patients with adjustment disorder into 6 groups by income for detailed analyses, while the number of patients was highest in very high income group and lowest in medical aid beneficiaries group consistently, higher number of patients was found in order of very high income group, high income group, middle income group, very low income group, low income group, and medical aid beneficiaries group in 2017. Considering the number of population in each 5 income quintile groups was approximately 7 times more than that in medical beneficiaries group, we could speculate that actual incidence of adjustment in medical beneficiaries group was also highest among 6 groups.

These results seemed to be in partial accordance with results from a recent study using the 11th revision of the International Classification of Disease (ICD-11) ${ }^{22}$ criteria of adjustment disorder. In 330 individuals who had job loss with involuntary causes, the unsatisfactory financial situation of the household of the participants was associated with a full adjustment diagnosis. ${ }^{23}$ This may be partly explained by the nature of stressors in adjustment disorder, as financial adversities were also one of significant stressor which could cause adjustment disorder in those who had vulnerabilities. ${ }^{22}$

In the current study, annual direct medical cost of adjustment disorder was continuously increased except 2015 and annual direct medical cost per person was reached 231.4 US dollars in 2017. Most direct medical cost was claimed by outpatient clinics and inpatient unit from psychiatric department. To our best of knowledge, this is the first study estimating the direct medical cost in adjustment disorder in general population.

There were a few limitations in the current study. As the current study used claims data from hospitals, patients who began treatment outside of a hospital were not included. The results of the current study would not reflect the precise incidence of adjustment disorder. In addition, as the current study was based on rather diagnostic codes recorded in claims data than standard interviews, diagnostic scales, and laboratory data, the diagnostic validity could be low and biased. Never- 
theless, considering relatively lack of evidences in adjustment disorder in general population, the current study has the strength to examine the diagnosed incidence for adjustment disorder using data recorded by physician in representative of the national population.

As global interest in stressor and related symptoms has been growing recently, proper information on adjustment disorder will not only allows us to accumulate more knowledge about these disorders themselves but also lead to more appropriate therapeutic interventions by improving the ability to cope with stressor-related symptoms and adversities. As the incidence and direct medical cost of adjustment were increased despite of social stigma, public education regarding identification and management of stress and its related sequelae as well as evidence-based treatment in medical settings should be provided.

\section{Availability of Data and Material}

The datasets generated or analyzed during the study are available from the corresponding author on reasonable request.

\section{Conflicts of Interest}

The authors have no potential conflicts of interest to disclose.

\section{Author Contributions}

Conceptualization: Kyo-Jin Yang, In-Hwan Oh, Saengryeol Park, Seung-Mi Choi, Jun-Won Hwang. Data curation: Kyo-Jin Yang, Si-Young Kim, In-Hwan Oh, Saengryeol Park, Jun-Won Hwang. Formal analysis: In-Hwan Oh, Saengryeol Park, Hyeon-Kyoung Cheong. Funding acquisition: Jun-Won Hwang. Investigation: Kyo-Jin Yang, Si-Young Kim, In-Hwan Oh, Saengryeol Park, Seung-Mi Choi, Jun-Won Hwang. Methodology: In-Hwan Oh, Saengryeol Park, Jun-Won Hwang. Project administration: Kyo-Jin Yang, Si-Young Kim, In-Hwan Oh, Saengryeol Park, Seung-Mi Choi, Jun-Won Hwang. Software: Saengryeol Park, Hyeon-Kyoung Cheong. Validation: Kyo-Jin Yang, Si-Young Kim, In-Hwan Oh, Saengryeol Park, Seung-Mi Choi, Jun-Won Hwang. Writing_-original draft: Kyo-Jin Yang, In-Hwan Oh, Saengryeol Park, Jun-Won Hwang. Writing-review \& editing: Kyo-Jin Yang, Si-Young Kim, In-Hwan Oh, Saengryeol Park, Seung-Mi Choi, Jun-Won Hwang.

\section{ORCID iDs}

Kyo-Jin Yang

Seung-Mi Choi

Si-Young Kim

In-Hwan Oh

Saengryeol Park

Hyeon-Kyoung Cheong

Jun-Won Hwang

\section{Funding Statement}

This study was supported by 2019 Research Grant from Kangwon National University (Grant No. 520190041). We also thank the NHIS for access to the claims database.

\section{REFERENCES}

1. American Psychiatric Association. Diagnostic and Statistical Manual of Mental Disorders. 5th Ed. Arlington, VA: American Psychiatric Association; 2013.

2. American Psychiatric Association. Diagnostic and Statistical Manual of
Mental Disorders. 3rd ed. Arlington, VA: American Psychiatric Association; 1980.

3. World Health Organization (WHO). The ICD-10 Classification of Mental and Behavioural Disorders. Geneva: World Health Organization; 1993.

4. Bachem R, Casey P. Adjustment disorder: A diagnosis whose time has come. J Affect Disord 2018;227:243-253.

5. Casey P. Adjustment disorder: new developments. Curr Psychiatry Rep 2014;16:451.

6. Maercker A, Forstmeier S, Enzler A, Krüsi G, Hörler E, Maier C, et al. Adjustment disorders, posttraumatic stress disorder, and depressive disorders in old age: findings from a community survey. Compr Psychiatry 2008;49:113-120.

7. Cornelius LR, Brouwer S, de Boer MR, Groothoff JW, van der Klink JJ. Development and validation of the Diagnostic Interview Adjustment Disorder (DIAD). Int J Methods Psychiatr Res 2014;23:192-207.

8. Mitchell AJ, Chan M, Bhatti H, Halton M, Grassi L, Johansen C, et al. Prevalence of depression, anxiety, and adjustment disorder in oncologi$\mathrm{cal}$, haematological, and palliative-care settings: a meta-analysis of 94 interview-based studies. Lancet Oncol 2011;12:160-174.

9. Myers JK, Weissman MM, Tischler GL, Holzer CE 3rd, Leaf PJ, Orvaschel H, et al. Six-month prevalence of psychiatric disorders in three communities 1980 to 1982. Arch Gen Psychiatry 1984;41:959-967.

10. Jenkins R, Lewis G, Bebbington P, Brugha T, Farrell M, Gill B, et al. The National Psychiatric Morbidity surveys of Great Britain--initial findings from the household survey. Psychol Med 1997;27:775-789.

11. Kessler RC, McGonagle KA, Zhao S, Nelson CB, Hughes M, Eshleman $\mathrm{S}$, et al. Lifetime and 12-month prevalence of DSM-III-R psychiatric disorders in the United States. Results from the National Comorbidity Survey. Arch Gen Psychiatry 1994;51:8-19.

12. Casey P, Maracy M, Kelly BD, Lehtinen V, Ayuso-Mateos JL, Dalgard OS, et al. Can adjustment disorder and depressive episode be distinguished? Results from ODIN. J Affect Disord 2006;92:291-297.

13. Maercker A, Forstmeier S, Pielmaier L, Spangenberg L, Brähler E, Glaesmer $\mathrm{H}$. Adjustment disorders: prevalence in a representative nationwide survey in Germany. Soc Psychiatry Psychiatr Epidemiol 2012;47:17451752.

14. Casey P. Adjustment disorder: epidemiology, diagnosis and treatment. CNS Drugs 2009;23:927-938.

15. Seong SC, Kim YY, Khang YH, Heon Park J, Kang HJ, Lee H, et al. Data resource profile: the National Health Information Database of the National Health Insurance Service in South Korea. Int J Epidemiol 2017;46: 799-800.

16. Ministry of Economy and Finance. Currency exchange statistical survey. Available at: http://www.index.go.kr/potal/stts/idxMain/selectPoSttsIdxSearch.do?idx_cd=1068. Updated 2020. Accessed Sep 30, 2020.

17. Cha KT, Kim IW, Koh SB, Hyun SJ, Park JH, Park JK, et al. The association of occupational stress with self-perceived fatigue in white collar employees. Korean J Occup Environ Med 2008;20:182-192.

18. Park JI, Jeon M. The stigma of mental illness in Korea. J Korean Neuropsychiatr Assoc 2016;55:299-309.

19. Choi Y. South Korea’s Unique Demography and Social Risks. In: Yang JJ, Klassen T, Editors. Retirement, Work, and Pensions in Ageing Korea. Abingdon, Oxon: Routledge, 2010, p.36-46.

20. Statistics Korea. Statistics of the Elderly. Daejon: Statistics Korea; 2011.

21. Choi YJ. Current Status and Challenges of the Elderly Welfare Policy. Sejong: Korean Legislation Research Institute; 2011.

22. World Health Organization (WHO). The ICD-11 Reference Guide. Geneva: World Health Organization; 2019.

23. Perkonigg A, Lorenz L, Maercker A. Prevalence and correlates of ICD11 adjustment disorder: Findings from the Zurich Adjustment Disorder Study. Int J Clin Health Psychol 2018;18:209-217. 